\title{
Herbivore nutrition supporting sustainable intensification and agro-ecological approaches
}

\author{
I. Cassar-Malek ${ }^{1 \dagger}$, R. Baumont ${ }^{1}$, A. Bannink ${ }^{2}$, I. Teixeira ${ }^{3}$, D. Mayberry ${ }^{4}$ and I. Kyriazakis ${ }^{5}$ \\ ${ }^{1}$ Université Clermont Auvergne, INRA, VetAgro Sup, UMR1213 Herbivores, F-63122 Saint-Genes-Champanelle, France; ${ }^{2}$ Wageningen Livestock Research, \\ Wageningen University \& Research, De Elst 1, 6708 WD, Wageningen, The Netherlands; ${ }^{3}$ UNESP - Universidade Estadual Paulista, School of Agricultural and \\ Veterinarian Sciences, Jaboticabal, SP 14884-900, Brazil; ${ }^{4}$ CSIRO Agriculture and Food, Queensland Bioscience Precinct, 306 Carmody Rd, St Lucia, Queensland 4067, \\ Australia; ${ }^{5}$ Agriculture, School of Natural and Environmental Sciences, Newcastle University, Newcastle upon Tyne, NE1 7RU, UK
}

Herbivores play a crucial role in food security, poverty alleviation and the sustainable development of developing economies. The International Symposium on the Nutrition of Herbivores provided a unique opportunity to discuss the role of herbivore nutrition in addressing the current challenges of producing higher quality livestock products more efficiently, with smaller impacts on the environment and animal welfare. Scientists from 46 countries had the opportunity to focus on issues of herbivore nutrition, and the challenges they face in a globalised and changing world. Along with 22 invited keynotes, 422 original communications were presented and are published in Advances in Animal Biosciences (Baumont et al., 2018).

As guest editors, we are pleased to publish the 22 full papers corresponding to the keynotes delivered at the Symposium across 11 sessions in this Supplement Issue of animal. The papers are authored by scientists from different countries to share an experienced vision on the various topics covered by the Symposium.

Session 1 focussed on herbivore nutrition in a globalised world. Mottet et al. (2018) emphasised the significant contribution of domestic herbivores to food security. They discussed the perspectives and the challenges for the sustainable development of the sector, including the development of adequate policies. Ayantunde et al. (2018) highlighted the role of herbivores in mixed farming systems and in supporting the livehoods of much of the rural population in sub-Saharan Africa. They identified the gaps to enhance agricultural sustainability in this area. Dumont et al. (2018) have reviewed the potentials of sustainable intensification and agroecology. They proposed that both approaches promote ways to reconcile natural resource management and food production in the long term, and perhaps could converge to shape the future of ruminant production.

Session 2 centred on rumen microbial ecosystems. Mizrahi and Jami (2018) examined the natural variations in the rumen microbiome, its potential impact on productivity of

\footnotetext{
${ }^{\dagger}$ E-mail: isabelle.cassar-malek@inra.fr
}

the host and the environment, and discussed the hurdles to modulations of the microbiome. Denman et al. (2018) addressed the application of meta-omics to rumen microbiota function and the potential benefit from the knowledge gained for manipulation of the microbiota towards a desired state.

Session 3 concentrated on the development of enhanced precision in herbivore nutrition. González et al. (2018) reviewed sensor and information technologies that allow monitoring of nutritional processes in individual animals, and discussed the challenges to integrate the increasing amount of data and computation of simulation models. Shalloo et al. (2018) argued for a user need-driven development of precision technologies. They reviewed the opportunities and challenges to implement precision technologies for an improved economical return in grass-based dairy systems.

Session 4 focussed on nutrition to improve the quality of herbivore products. Toral et al. (2018) compiled studies on nutritional strategies to manipulate ruminal lipid metabolism and to raise beneficial fatty acids in meat and milk. Among topics with significant prospects for the future are the manipulation of ruminal biohydrogenation, evaluation of alternative feed resources including by-products rich in active compounds, and advances in microalgae production. Ladeira et al. (2018) appraised studies on nutrigenomics of marbling. They showed how nutrition affects expression of genes involved in adipogenesis, lipogenesis and fatty acid profile of muscle, and how this knowledge will permit nutritionists to modulate ruminant meat quality during the prenatal or postnatal life.

Session 5 centred on feed resources and sustainable diets. Halmemies-Beauchet-Filleau et al. (2018) gave an overview of the current knowledge on alternative and novel feeds for ruminant systems both in temperate and tropical environments. They highlighted the potential of various novel and unexploited feeds to replace or supplement traditional crops used in ruminant rations. van Lingen et al. (2018) appraised the relationships between dairy cattle feed resources, animal characteristics, methane $\left(\mathrm{CH}_{4}\right)$ emissions and excreta (digestible volatile solids and nitrogen) through the use of 
univariate and multivariate mixed-effects models. The analysis revealed potential trade-offs between enteric $\mathrm{CH}_{4}$ emissions and excretion of volatile solids and nitrogen (N) and identifies knowledge gaps related to impact of dairy nutrition and management interventions.

Following this, Session 6 addressed two areas in relation to feed conversion efficiency and reduction of excreta. Cantalapiedra-Hijar et al. (2018) integrated the knowledge on the biological determinants and molecular pathways of between-animal variation in feed efficiency in growing beef cattle. They suggested that the role of feeding and digestiverelated mechanisms in feed efficiency could be minor, and emphasised the contribution of metabolic pathways and non-productive functions to efficiency. Løvendahl et al. (2018) discussed how $\mathrm{CH}_{4}$ emissions and feed efficiency traits are related to each other, and the many interacting biological factors that may influence both trait groups. Understanding the underlying mechanisms remains a challenge and may improve the ability to select dairy cattle for improved feed efficiency and reduced $\mathrm{CH}_{4}$ emissions.

Session 7 was dedicated to the interactions between nutrition, genetics and environment. Roche et al. (2018) discussed the influence of genotype $\times$ environment interactions on the robustness of dairy cows for grazing systems. The authors suggested that in the future there will be an increased emphasis on the evaluation of important traits for the quality of life of the animal and the reduction of the environmental footprint. Chavatte-Palmer et al. (2018) reviewed the effects of nutrition epigenetic marks in mammalian herbivores, and highlighted the need for research on nutritional strategies to modulate the epigenetic machinery and developmental programming.

Session 8 was dedicated to wild herbivores. Gordon (2018) highlighted that livestock production increasingly influences wildlife across the globe, mainly through ancillary activities. Land sparing, land-sharing between livestock production and wildlife, and win-win strategies are key issues that need to be addressed further. Improving the efficiency of livestock production will be key to successful strategies to maintain wildlife. Forbey et al. (2018) described a physiological model to help identify key physiological mechanisms that underlie diet-based ecological adaptations. The model is based on how both toxic and nutritional food constituents are metabolically processed, and provides a mechanistic link between foraging decisions in vertebrate herbivores and population consequences.

Session 9 focussed on nutritional management of health and welfare. Plaizier et al. (2018) argued that efficacy of nutritional strategies to prevent gastrointestinal health disorders in dairy cows may be improved. The mechanisms through which nutrition and feed supplements or additives enhance gastrointestinal health have to be unravelled. Neave et al. (2018) outlined evidence that individual variability in feeding behaviour of domesticated ruminants is associated with the personality of the individual. This highlights that an understanding of personality can help to adapt the management of animals to the needs of the individual in order to improve animal welfare and productivity.
Session 10 centred on adaptation of herbivores to climate changes and diverse environments, a key challenge for the future of livestock production. Sejian et al. (2018) discussed the need to identify phenotypic and genotypic indicators of heat stress susceptibility that can be included in breeding programs in an effort to develop thermo-tolerant breeds using marker-assisted selection. Henry et al. (2018) reviewed the research on the impact of climate change on ruminant livestock production and the effective adaptation together with evidence of practical adaptive management, and proposed potential strategies and gaps in knowledge to be filled.

The final session focussed on converting scientific knowledge into innovation in herbivore nutrition. Lapierre et al. (2018) presented a case study comparing different protein feeding systems in their ability to predict milk protein yield in dairy cows. An adequate prediction of milk protein yield will allow a reduced protein content in dairy rations, which has the dual effect of decreasing feed cost and increasing the farm net income while reducing $\mathrm{N}$ excretion and emissions. The comparative study highlights the importance to take into account the variable efficiency of utilisation of supplied protein. This concept should probably also be adopted for the supply of essential amino acids.

We hope reading this special issue of animal will help you learn more about herbivore nutrition and find inspiration for future research and development in this area.

\section{Acknowledgements}

We would like to thank all members of the International Advisory Committee of the Symposium, the Local Scientific Committee and to all the reviewers who contributed to the preparation of this supplement issue.

\section{Declaration of interest \\ None}

\section{Ethics statement}

None

\section{Software and data repository resources}

None

\section{References}

Ayantunde AA, Duncan AJ, van Wijk MT and Thorne P 2018. Review: Role of herbivores in sustainable agriculture in Sub-Saharan Africa. Animal, 12 s199209.

Baumont R, Silberberg M and Cassar-Malek I (eds) 2018. Proceedings of the 10th International Symposium on the Nutrition of Herbivores (Abstracts). Advances in Animal Biosciences 9, 1-500.

Cantalapiedra-Hijar G, Abo-Ismail M, Carstens GE, Guan LL, Hegarty R, Kenny DA, McGee M, Plastow G, Relling A and Ortigues-Marty I 2018. Review: Biological determinants of between-animal variation in feed efficiency of growing beef cattle. Animal, 12 s321-335.

Chavatte-Palmer P, Velazquez MA, Jammes H and Duranthon V 2018. Review: Epigenetics, developmental programming and nutrition in herbivores. Animal, 12 s363-371.

Denman SE, Morgavi DP and McSweeney CS 2018. Review: The application of omics to rumen microbiota function. Animal, 12 s233-245. 
Dumont B, Groot JCJ and Tichit M 2018. Review: Make ruminants green again how can sustainable intensification and agroecology converge for a better future? Animal, 12 s210-219.

Forbey JS, Liu R, Caughlin TT, Matocq MD, Vucetich JA, Kohl KD, Dearing MD and Felton AM 2018. Review: Using physiologically based models to predict population responses to phytochemicals by wild vertebrate herbivores. Animal 12 s383-398.

González LA, Kyriazakis I and Tedeschi LO 2018. Review: Precision nutrition of herbivores: approaches, challenges and potential gains. Animal, 12 s246-261.

Gordon IJ 2018. Review: Livestock production increasingly influences wildlife across the globe. Animal, 12 s372-382.

Halmemies-Beauchet-Filleau A, Rinne M, Lamminen M, Mapato C, Ampapon T, Wanapat M and Vanhatalo A 2018. Review: Alternative and novel feeds for ruminants: nutritive value, product quality and environmental aspects. Animal, 12 s295-309.

Henry BK, Eckard RJ and Beauchemin KA 2018. Review: Adaptation of ruminant livestock production systems to climate changes. Animal, 12 s445-456.

Ladeira MM, Schoonmaker JP, Swanson KC, Duckett SK, Gionbelli MP, Rodrigues LM and Teixeira PD 2018. Review: Nutrigenomics of marbling and fatty acid profile in ruminant meat. Animal, 12 s282-294.

Lapierre H, Larsen M, Sauvant D, Van Amburgh ME and Van Duinkerken G 2018. Review: Converting nutritional knowledge into feeding practices: a case study comparing different protein feeding systems for dairy cows. Animal, 12 s457466.

Løvendahl P, Difford GF, Li B, Chagunda MGG, Huhtanen P, Lidauer MH, Lassen $J$ and Lund $P$ 2018. Review: Selecting for improved feed efficiency and reduced methane emissions in dairy cattle. Animal, 12 s336-349.
Mizrahi I and Jami E 2018. Review: The compositional variation of the rumen microbiome and its effect on host performance and methane emission. Animal, 12 s220-232.

Mottet A, Teillard F, Boettcher P, De' Besi G and Besbes B 2018. Review: Domestic herbivores and food security: current contribution, trends and challenges for a sustainable development. Animal, 12 s188-198.

Neave HW, Weary DM and von Keyserlingk MAG 2018. Review: Individual variability in feeding behaviour of domesticated ruminants. Animal, 12 s419-430.

Plaizier JC, Danesh Mesgaran M, Derakhshani H, Golder H, Khafipour E, Kleen JL Lean I, Loor J, Penner G and Zebeli Q 2018. Review: Enhancing gastrointestinal health in dairy cows. Animal, 12 s399-418.

Roche JR, Berry DP, Delaby L, Dillon PG, Horan B, Macdonald KA and Neal M 2018. Review: New considerations to refine breeding objectives of dairy cows for increasing robustness and sustainability of grass-based milk production systems. Animal, 12 s350-362.

Sejian V, Bhatta R, Gaughan JB, Dunshea FR and Lacetera N 2018. Review: Adaptation of animals to heat stress. Animal, 12 s431-444.

Shalloo L, 0 'Donovan M, Leso L, Werner J, Ruelle E, Geoghegan A, Delaby L and O'Leary N 2018. Review: Grass based dairy systems, data, and precision technologies. Animal, 12 s262-271.

Toral PG, Monahan FJ, Hervás G, Frutos P and Moloney AP 2018. Review: Modulating ruminal lipid metabolism to improve the fatty acid composition of meat and milk. Challenges and opportunities. Animal, 12 s272-281.

van Lingen HJ, Fadel JG, Bannink A, Dijkstra J, Tricarico JM, Pacheco D, Casper DP and Kebreab E 2018. Multi-criteria evaluation of dairy cattle feed resources and animal characteristics for nutritive and environmental impacts. Animal, 12 s310-320. 